\title{
Corrosion behaviour of the titanium beta alloy nanotubular surface in the presence of fluoride ions
}

\author{
Fojt J. ${ }^{1}$, Hybasek V. ${ }^{1}$, Jarolimova P. ${ }^{1}$, Pruchova E. ${ }^{l}$, Joska L. ${ }^{1}$, Malek J. ${ }^{2}$ \\ ${ }^{1}$ University of Chemistry and Technology, Prague \\ ${ }^{2}$ UJP Prague \\ E-mail: fojtj@vscht.cz
}

The titanium bioactivity could be increased by surface nanostructuring. Titanium alloys are using for dental implants manufacturing. It represents a specific problem because of using of the dental treatments with high concentration of fluoride ions and with acidic $p H$. The corrosion resistance of nanostructured surface of titanium beta alloy in environments with fluoride ions was examined by common electrochemical technique. The electrochemical impedance measurement showed high corrosion resistance in physiological solution. The fluoride ions have expected negative influence on corrosion behaviour of the layer. The nanotube bottom was preferentially attacked which resulted in layer undercoroding and its detachment.

\section{INTRODUCTION}

Titanium and Ti6Al4V alloy are among the most modern metallic biomaterials. Their applications are mainly in orthopaedics and dental implantology due to their low density, high fatigue strength, excellent corrosion resistance, biocompatibility and osseointegration ability [1-3]. However, these materials may exhibit the considerable degree of biomechanical incompatibility because of the relatively high modulus of elasticity, approximately $110 \mathrm{GPa}$, compared to the compact bone (10-25 GPa) [4]. This incompatibility may cause the "stress shielding effect". Thereafter the bone tissue is not sufficiently regenerated and a bone-implant binding could be lost $[5,6]$. Because of that, current materials research has been focused on $\beta$ titanium alloys which have lower Young's modulus (approximately 40-80 GPa) [7, 8]. The major alloying elements stabilizing the $\beta$ phase are $\mathrm{Nb}, \mathrm{Ta}$ and $\mathrm{Zr}$ [9]. These alloys are in principle bioinert. Appropriate surface modifications, e.g. organic coatings, plasma spraying of hydroxyapatite and especially the formation of an ordered nanostructure on the surface of the material are used to enhance bioactivity. The larger area of the nanostructured surface, compared to the polished surface, allows the adsorption of biologically active substances, such as proteins [10-12]. The nanostructuring of the commercially pure titanium and the Ti6A14V alloy is well described $[13,14]$. Also, several studies about nanostructuring of the titanium beta alloys were published [15-17]. In addition to increasing bioactivity, nanostructuring also has a positive effect on corrosion resistance [18]. Nanotubes act as an effective barrier layer. Its corrosion resistance could be increased by heat treatment $[19,20]$ and influenced, together with apatite-forming ability, by tubes diameter and length tuning [21]. The corrosion resistance of the nanostructured surfaces in phosphate buffered solution containing serum proteins was higher in comparison with flat surface [22]. Jang et al published increase of the current density e.g. decreased corrosion resistance of the nanotubes formed on $\mathrm{Ti}-\mathrm{xNb}$ systems [23]. Same results were stated by Kim et al in the case of nanotubes prepared on Ti-xZr alloys [24]. However, increased corrosion currents could be caused by differences in geometrical and real surface [25]. Application of titanium and its alloys in dental implantology represent a specific problem, because of they get in contact with fluoride ions coming from dental treatment products. Fluorides can cause destruction of passive layer and substantially increase corrosion rate of the implant [26-29]. The nanostructured surface could be used on dental implants, so there is a danger of the contact of the nanotubes with highly aggressive environment specific for dentistry.

The main purpose of this work is to describe the stability of the nanostructured surface in the presence of the fluoride ions and to point out on the possible risks when such treated surface is used in dental applications. 


\section{MATERIALS AND METHODS}

\section{Specimens preparation and surface characterization}

The beta-titanium alloy with nominal chemical composition Ti-35Nb-2Zr was prepared via powder metallurgy process. Elemental powders were used purity of at least $99.5 \%$ and grain size -325 mesh (i.e. average diameter $<44 \mu \mathrm{m}$ ). Powders were mixed and filled in moulds under protective Ar atmosphere. Specimens were cold isostatically pressed (CIP) at $400 \mathrm{MPa}$ and subsequently sintered. Sintering has been carried out in a vacuum furnace. The specimens were heated up to $800{ }^{\circ} \mathrm{C}$ and hold for 1 hour and subsequently heated to the sintering temperature of $1300{ }^{\circ} \mathrm{C}$ and sintered for 20 hours. Sintered specimens were machined into cylinders of about $33 \mathrm{~mm}$ in diameter and forged at $1000{ }^{\circ} \mathrm{C}$ to $17.5 \mathrm{~mm}$ diameter (in multiple steps). The forged specimens were annealed at $1000^{\circ} \mathrm{C}$ for $0.5 \mathrm{~h}$ and water quenched. Furthermore, they were machined and cut into cylindrical samples with $16 \mathrm{~mm}$ in diameter and about $3 \mathrm{~mm}$ in thickness.

These specimens were wet ground (up to P2500 FEPA) and polished using an alkaline suspension of pyrogenic silica with a particle size of $12 \mu \mathrm{m}$ (Fumed Silica, pH 9.5-10, Hanyko). Polished specimens were rinsed with water and ethanol, then cleaned in an ultrasonic bath for 10 minutes and dried by hot air. The metallographic structure was studied after etching by Kroll's agent.

The nanostructures were prepared in an electrolyte containing $11.6 \mathrm{wt} \%$ of $\left(\mathrm{NH}_{4}\right)_{2} \mathrm{SO}_{4}$ and 1 wt $\%$ of $\mathrm{NH}_{4} \mathrm{~F}$. The $\mathrm{pH}$ value of the solution was adjusted to 5 by sulfuric acid. Anodic oxidation consisted of linear potential growth to $20 \mathrm{~V}$ at a rate of $100 \mathrm{mV} / \mathrm{s}, 2000 \mathrm{~s}$ duration at this potential value and then decrease to $0 \mathrm{~V}$ (sweep rate $100 \mathrm{mV} / \mathrm{s}$ ). The process of anodic oxidation was controlled by potentiostat Jaissle Potentiostat Galvanostat IMP 88 PC $-200 \mathrm{~V}$. The adhesion of the nanostructured layer with the basic material was tested by a pull-off test according to ASTM F 1147-99 and ASTM C 633-79 using the Scotch-Weld EXP Adhesive DP 490 glue.

The resulting nanostructures were observed with a TESCAN VEGA 3 LMU scanning electron microscope. Diameter and length of nanotubes were evaluated by image analysis of ten image fields using ImageJ software.

\section{Electrochemical measurement}

Electrochemical measurements were realized at $37.0 \pm 0.1{ }^{\circ} \mathrm{C}$ in thermostated corrosion cell. Silversilver chloride electrode with $3 \mathrm{~mol} \mathrm{l}^{-1} \mathrm{KCl}$ (SSCE) was used as a reference and two glassy carbon rods were used as counter electrodes. The open circuit potential
(OCP) was monitored for 12 hours. The electrochemical impedance spectra were measured in the frequency range from $60 \mathrm{kHz}$ to $1.6 \mathrm{mHz}$ with an amplitude of AC signal $10 \mathrm{mV}$. The potentiodynamic curve was scanned within the potential range from $-50 \mathrm{mV} / \mathrm{OCP}$ to $1 \mathrm{~V} / \mathrm{SSCE}$. Measurements were performed in physiological solution $(9 \mathrm{~g} / \mathrm{l} \mathrm{NaCl})$ with unadjusted $\mathrm{pH}$ and with $\mathrm{pH}$ adjusted to 4.2 (phthalate buffer). Fluoride ions in the form of $\mathrm{NaF}$ were added into the solutions in concentrations $1000 \mathrm{ppm}$ (unadjusted $\mathrm{pH}$ ) and $200 \mathrm{ppm}$ (pH 4.2). For comparative purposes, measurement with a specimen with the polished surface was made in physiological solution with a $\mathrm{pH}$ value of 4.2 and $1000 \mathrm{ppm}$ fluoride ions (environment will be abbreviated as $\mathrm{PS} / \mathrm{pH} / \mathrm{F}$ concentration).

\section{RESULTS AND DISCUSSION}

\section{Specimens characterization}

The Ti-35Nb-2Zr alloy consisted of the homogeneous $\beta$ structure with almost equal grain geometry of size $128.3 \pm 22.1 \mu \mathrm{m}$ (Fig. 1a). The mechanical properties of the alloy have been described in our previous study [8]. Figure $1 \mathrm{~b}$ shows nanostructured surface prepared by anodic oxidation. The entire surface of the specimen was homogeneously nanostructured with a major internal tube diameter of about $35 \mathrm{~nm}$. The histogram of nanotubes diameter distribution is shown in Figure 1c. The layer thickness of approximately $4 \mu \mathrm{m}$ was evaluated from tubes cross-section. The compact interlayer was formed between nanotubes and base material as a result of the controlled potential decrease in the last step of anodization [30]. This layer guarantees increased adhesion of the nanostructure with the base metal. The pull-off strength was $34 \pm 2 \mathrm{MPa}$, which is more than sufficient value for layers used in implantology. The minimum bonding strength of $18 \mathrm{MPa}$ is required for biomedical coatings [31].

\section{Corrosion behaviour}

The physiological solution was chosen for the description of corrosion behaviour. It represents the simplest model of the human body environment. Due to the fact that the studied alloy is considered for use in the field of dental implantology, measurement was carried out also in the environment with fluoride ions, which are a common part of dental hygiene products [26, 32]. Measurements were realized in the physiological solution with unadjusted $\mathrm{pH}$ value and also with $\mathrm{pH}$ 4.2. Since the results in these two environments did not differ substantially, the following data will be presented only for the solution with $\mathrm{pH}$ 4.2.

Open circuit potential of both the polished and nanostructured surface after 12 hours exposure in the en- 
vironments mentioned above is summarised in Table 1. The potential values clearly exemplify the corrosive aggressiveness of the environments. In the presence of fluoride ions, both the corrosion potential of the polished specimen and the nanostructured surface decreased. The decrease of the $\mathrm{pH}$ value in combination with fluoride ions results in a subsequent diminution of the open circuit potential. However, there was no decrease of the potential to values indicating the active dissolution of titanium, i.e. about $-1 \mathrm{~V} / \mathrm{SSCE}[26,28,33]$. In the case of a nanostructured surface, the measured values were

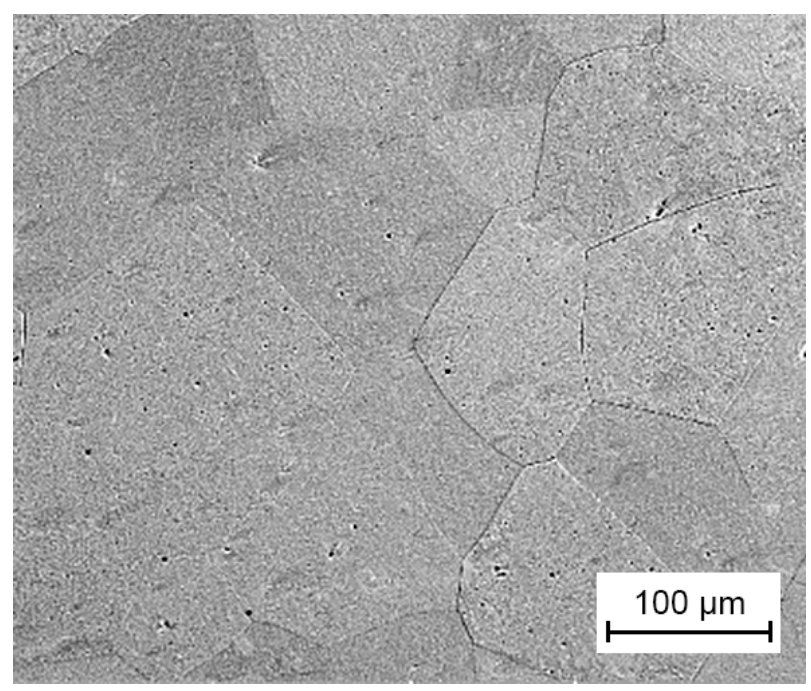

a)

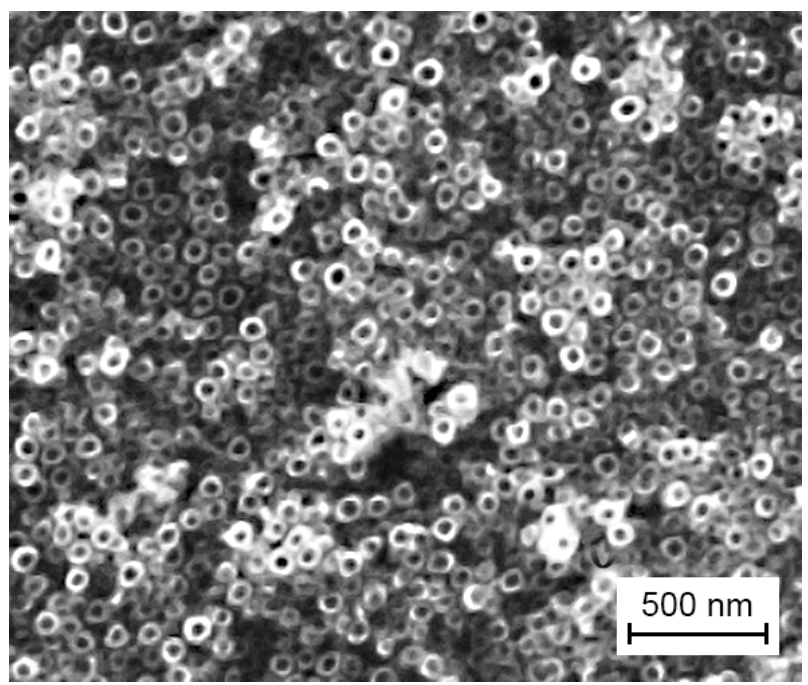

b) higher than for the polished surface. This behaviour results from the surface state - the polished surface consists of a native passive layer which is relatively thin and contains also non-stoichiometric oxides, while the nanostructure is formed by the thick oxide layer containing single elements of the alloy in their highest oxidation state. Detailed analysis of the nanostructure was described in our previous study [25].

Impedance spectra of the polished surfaces in given environments are shown in Figure 2a. The impedance spectrum in the physiological solution corresponds to the spectrum of passive surface and was evaluated by the equivalent circuit shown in Figure 3a. This circuit describes the behaviour of a two-layer structure where R1 and CPE1 correspond to the pore electrolyte resistance and the capacitance of the outer porous layer. The R2 and CPE2 describe the charge transfer resistance and the capacitance of the inner phase boundary respectively. This circuit is usually used for titanium and its alloys impedance spectra fitting [34-36]. In case of the specimen exposed to both fluoride ion containing environments, the spectra were fitted with the circuit shown in Figure $3 b$, which is common for a corroding metal [37]. In the spectrum measured in the solution containing $200 \mathrm{ppm} \mathrm{F}^{-}$, it is possible to see a significant decrease in phase angle accompanied by a slight decrease in impedance modulus in the low frequency range. The impedance modulus is increasing subsequently. The pseudoinductive loop is clearly visible in the Nyquist presentation (Fig. 2b). This loop reflects precipitation of corrosion products [38-40] and was not considered in spectra evaluation.

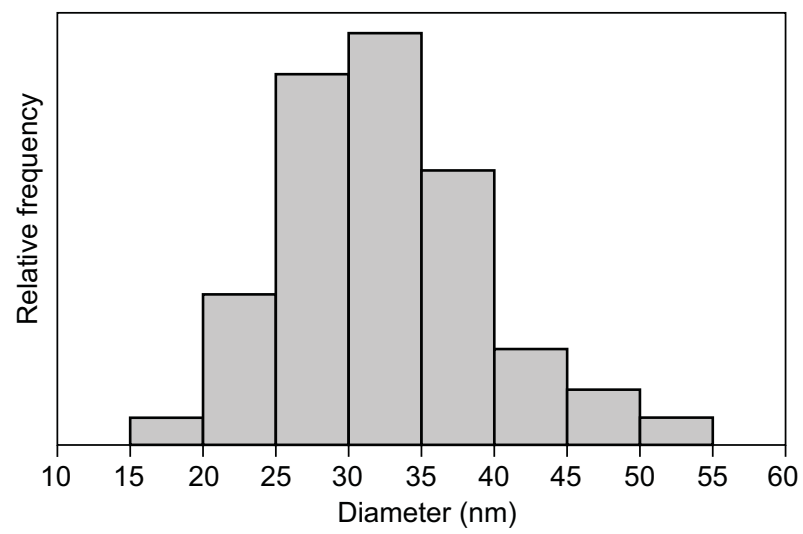

c)

Fig. 1. Ti-35Nb-2Zr alloy microstructure (a), nanostructured surface (b) and distribution of the tubes inner diameter (c)

Tab. 1. Open circuit potential of the Ti-35Nb-2Zr alloy with the different superficial state in physiological solutions

\begin{tabular}{|l|c|c|c|}
\hline E (V/SSCE) & PS/4.2/0ppmF & PS/n.a./1000ppmF & PS/4.2/200ppmF \\
\hline Polished & -65 & -234 & -526 \\
\hline Nanostructured & -27 & -121 & -375 \\
\hline
\end{tabular}


The impedance spectra of the nanostructured surface are more complicated. In case of exposures in physiological solution and a physiological solution containing $1000 \mathrm{ppm} \mathrm{F}^{-}$, the capacitive behaviour of the surface can be observed, which is reflected by the decrease in phase angle in the low frequency range. In the case of measurement in physiological solution with $200 \mathrm{ppm} \mathrm{F}^{-}$, the phase angle limits to zero at low frequencies indicating the presence of corrosion process.

Impedance spectra of the nanostructured surface in the physiological solution without fluorides and in physiological solution with $1000 \mathrm{ppm} \mathrm{F}^{-}$were fitted by an equivalent circuit in Figure $3 \mathrm{c}$. The individual elements have the same meaning as described above. Added R3 and CPE3 model barrier layer between tubes and metal. This model was used for nanotubes spectra fitting in several works [41-44].

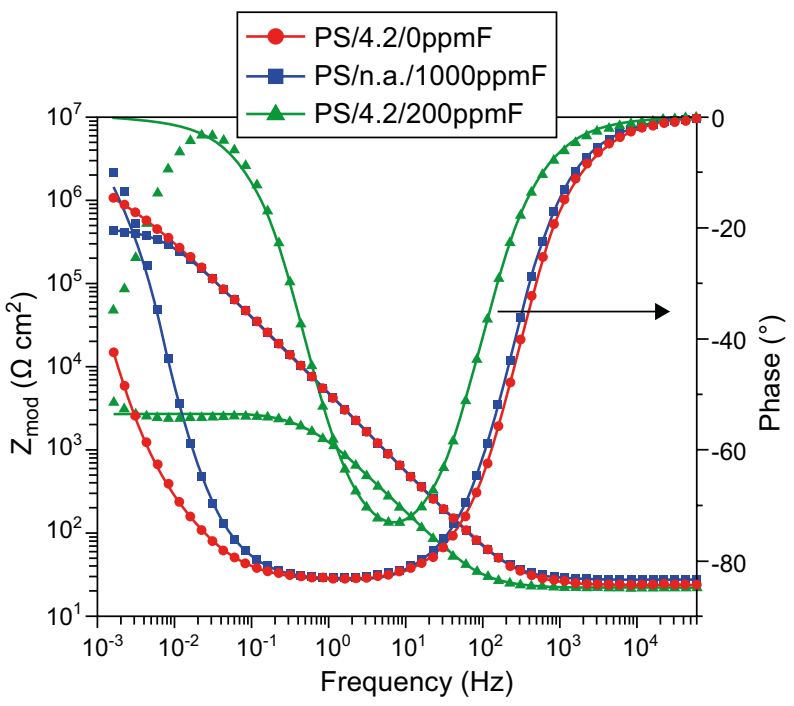

a)

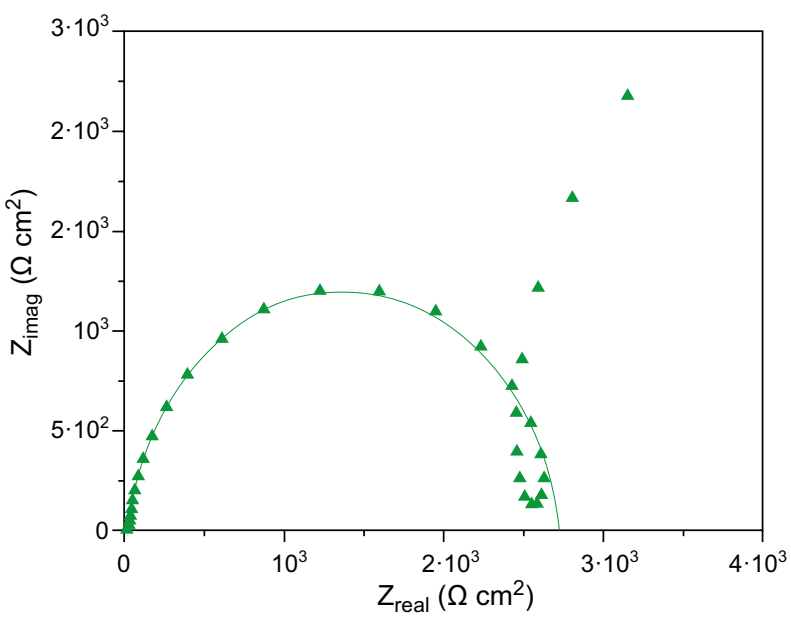

b)
The results of the impedance spectra analysis are summarized in Table 2. In the physiological solution, both the polished and nanostructured surfaces reached high total resistance values. The lower resistance of the nanostructured surface was caused by higher real surface than the relative geometrical [25]. The resistance of the pore solution (R1) was lower for the nanostructured surface. This was caused by large nanotubes diameter in comparison with pores in the native passive layer. The highest resistance was achieved by a compact interlayer, which is the main element involved in the corrosion resistance of the nanostructured material.

It is possible to state the decrease in the order of magnitude of the polished surface charge transfer resistance in physiological solution with $1000 \mathrm{ppm} \mathrm{F}^{-}$in comparison with the environment without fluorides. This is due to the ongoing corrosion process, which is also confirmed by the EIS analysis - the appropriate equivalent circuit is model of corroding metal (Fig. 3b). There is no significant change of the values of the individual circuit elements in case of the nanostructured surface. The negative effect of fluoride ions on the corrosion resistance of the nanotubes was also indicated in Munirathinam et al [45]. They observed an increase in corrosion currents in the case of nanotubes after immersion in fluorides containing electrolyte. However, measurement was realised in fluoride free environment.

The corrosion process was more intensive in physiological solution with $\mathrm{pH}$ adjusted to 4.2 containing $200 \mathrm{ppm}$ of fluoride ions. This is evidenced by both the relatively low $\mathrm{R} 2$ value and by the increased capacitance of CPE2 as well. This corresponds to the massive thinning of the surface layer. The pseudoinductive loop was not included in the analysis. However, the resistance

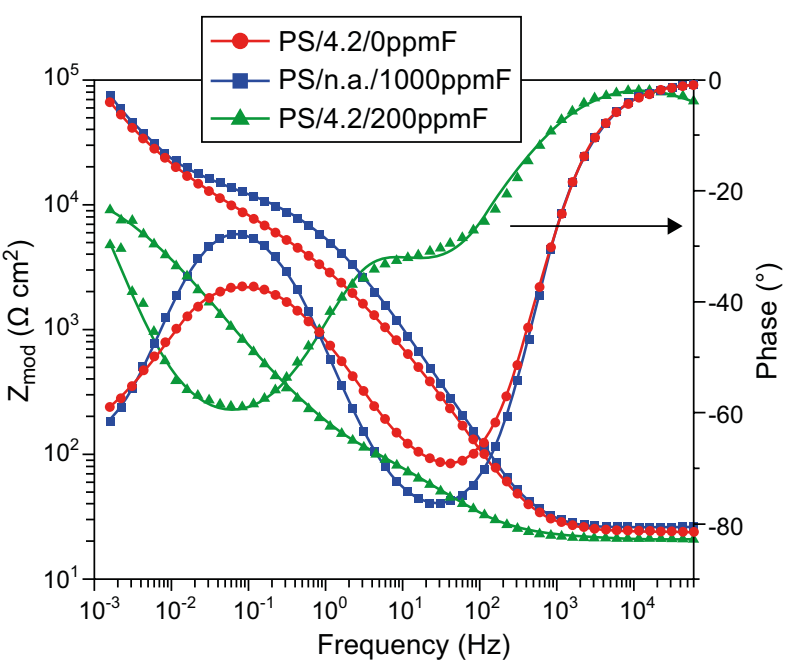

c)

Fig. 2. The electrochemical impedance spectra of Ti-35Nb-2Zr with a polished surface (a), pseudoinductive loop of the polished surface in PS/4.2/200 ppm F- (b) and Ti-35Nb-2Zr with the nanostructured surface (c). Symbols are measured data, line corresponds to the fit 
Tab. 2. Results of the impedance spectra analysis

\begin{tabular}{|l|c|c|c|c|c|c|}
\hline & \multicolumn{3}{|c|}{ Polished surface } & \multicolumn{3}{c|}{ Nanotubes } \\
\hline & PS/4.2/0 & PS/n.a./1000 & PS/4.2/200 & PS/4.2/0 & PS/n.a./1000 & PS/4.2/200 \\
\hline $\mathrm{R} 1\left(\Omega \mathrm{cm}^{2}\right)$ & $6.97 \cdot 10^{5}$ & - & - & 184 & 320 & 119 \\
\hline $\mathrm{R} 2\left(\Omega \mathrm{cm}^{2}\right)$ & $1.06 \cdot 10^{6}$ & $4.49 \cdot 10^{5}$ & $2.7 \cdot 10^{3}$ & $2.88 \cdot 10^{4}$ & $2.35 \cdot 10^{4}$ & $1.31 \cdot 10^{4}$ \\
\hline $\mathrm{R} 3\left(\Omega \mathrm{cm}^{2}\right)$ & - & - & - & $4.76 \cdot 10^{5}$ & $5.35 \cdot 10^{5}$ & - \\
\hline $\mathrm{CPE} 1\left(\mathrm{~S} \mathrm{~s}^{\alpha} \mathrm{cm}^{-2}\right)$ & $3.71 \cdot 10^{-5}$ & - & - & $2.34 \cdot 10^{-5}$ & $1.89 \cdot 10^{-5}$ & $5.45 \cdot 10^{-4}$ \\
\hline $\mathrm{CPE} 2\left(\mathrm{~S} \mathrm{~s}^{\alpha} \mathrm{cm}^{-2}\right)$ & $1.58 \cdot 10^{-5}$ & $3.78 \cdot 10^{-5}$ & $1.22 \cdot 10^{-4}$ & $1.25 \cdot 10^{-4}$ & $7.29 \cdot 10^{-5}$ & $1.39 \cdot 10^{-4}$ \\
\hline $\mathrm{CPE} 3\left(\mathrm{~S} \mathrm{~s}^{\alpha} \mathrm{cm}^{-2}\right)$ & - & - & - & $9.98 \cdot 10^{-4}$ & $1 \cdot 10^{-3}$ & - \\
\hline
\end{tabular}

values, as well as open circuit potential, do not drop to the active dissolution range of titanium. To obtain data for active dissolution of the alloy, the measurement in physiological solution with $\mathrm{pH} 4.2$ containing $1000 \mathrm{ppm}$ of fluoride ions was realised. The open circuit potential and charge transfer resistance were approximately $-940 \mathrm{mV} / \mathrm{SSCE}$ and $600 \Omega \mathrm{cm}^{2}$ respectively. The charge transfer resistance of the nanostructured surface in $\mathrm{PS} / 4.2 / 200$ was in the order of magnitude higher than that of the untreated surface. Its impedance spectrum was evaluated using the equivalent circuit in Figure $3 \mathrm{a}$. Thus, one can assume that the interlayer between the

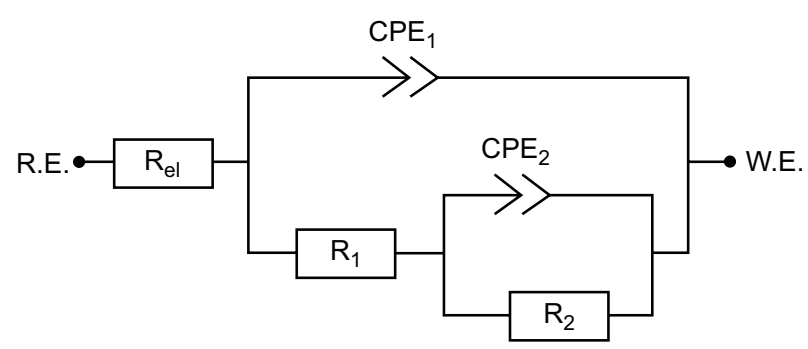

a)

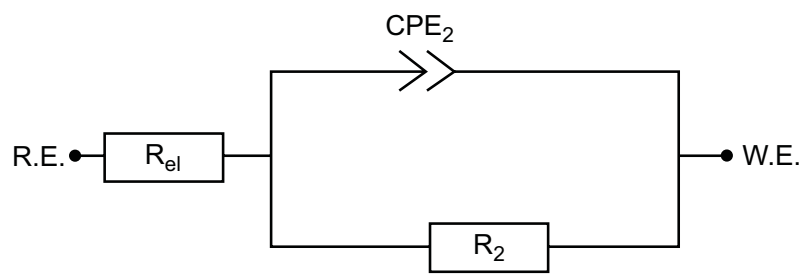

b)

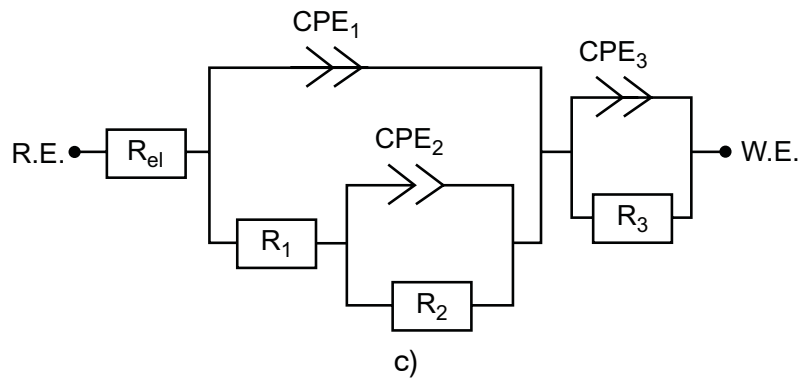

Fig. 3. Equivalent circuits used for impedance spectra evaluating nanotubes and the surface of the material do not act as a barrier anymore. Compared to the polished surface, nanotubes showed only a slight decrease in charge transfer resistance. This is due to the localization of corrosion at the bottom of nanotubes where the thinnest oxide layer is. Because of this localization, the actively corroding surface is smaller than that of the polished sample, where the entire exposed surface corrodes. The open circuit potential is thus affected by the large nonattacked surface.

According to the potentiodynamic curves in physiological solution without fluoride ions (an environment without acceleration of corrosion processes), the real exposed area of the nanostructured surface caused an order increase in the passive current density which in this case corresponds predominantly to electrolyte reactions (Fig. 4) [25]. This trend is not so obvious in physiological solution with 1000 ppm $\mathrm{F}^{-}$. The corrosion reaction is dominant in this case. However, the thickened oxide layer underneath the nanostructure shifts the corrosion potential to the more positive values and the current density to lower values in comparison with a polished surface. Only a small increase in corrosion current density compared to a solution without fluoride ions indicates that no active corrosion has occurred yet on any type of specimens.

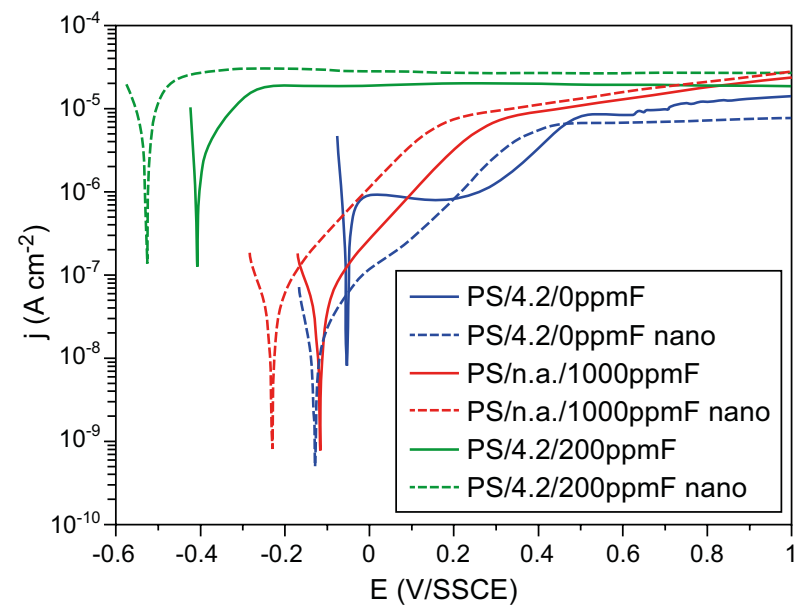

Fig. 4. Potentiodynamic curves of studied materials 


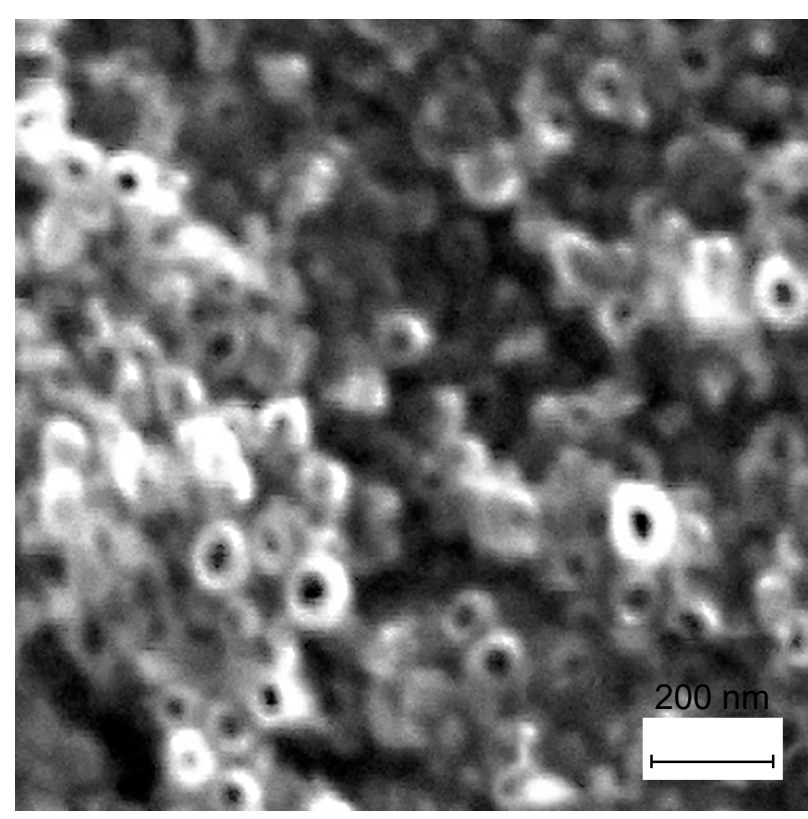

Fig. 5. Nanotubes bottom after exposure in PS/4.2/200 ppm F

A significant decrease in corrosion potential as well as the increase in corrosion current density for both types of specimens in solution with $\mathrm{pH} 4.2$ and $200 \mathrm{ppm} \mathrm{F}^{-}$shows that the part of the oxide layer on the surface has been already dissolved in this environment. The corrosion current density of the same order for both nanostructured and polished material also points to the localization of corrosion at the bottom of nanotubes. Lower current density and more positive corrosion potential of the nanostructured specimen are due to a smaller corrosion area. This localized corrosion is also evident in the SEM image of the nanostructure underneath (Fig 5.). There are clearly visible etched tube bottoms. The layer of the tubes was easily detached by common tape and thus tubes bottom could be documented. Dissolved tubes bottom lead to the layer under corroding and to the loss of the adhesion. This could be a limiting factor in the dentistry because of the possible risk of the loss of the connection between the nanostructured implant and surrounding tissue and also a technological problem. The nanostructuring electrolyte is very aggressive and in the case when the sample with nanotube was not removed from bath immediately after the process, the corrosion of the bottom of the tubes could occur.

\section{CONCLUSION}

The nanotubular oxidic surface was successfully prepared on the $\mathrm{Ti}-35 \mathrm{Nb}-2 \mathrm{Zr}$ beta titanium alloy which was manufactured by powder metallurgy. The corrosion behaviour of nanotubes was comparable with a polished surface in the physiological saline solution. Increased corrosion resistance of nanostructured samples was observed in the electrolytes with fluoride ions. The $\mathrm{pH}$ decrease in combination with fluorides caused dissolution of the tubes bottom and subsequent layer under corroding. The adhesion of the nanostructure was lost as a consequence of this process. This is limiting factor for using this surface in dentistry.

\section{Acknowledgement}

This work was supported by Czech Science Foundation [grant number 16-14758S].

\section{REFERENCES}

1. Zhang, L.; Webster, T. J., Nanotechnology and nanomaterials: Promises for improved tissue regeneration. Nano Today 2009, 4 (1), 66-80.

2. Niinomi, M., Recent research and development in titanium alloys for biomedical applications and health-care goods. Science and Technology of Advanced Materials 2003, 4 (5), 445-454.

3. Elias, C. N., Biomedical Applications of Titanium and its Alloys. Biological Materials Science 2008.

4. Guillemot, F., Recent advances in the design of titanium alloys for orthopedic applications. Expert Review of Medical Devices 2005, 2 (6), 741-748.

5. Bahraminasab, M., et al., Aseptic loosening of femoral components - Materials engineering and design considerations. Materials \& Design 2013, 44, 155-163.

6. Bahraminasab, M., et al., Aseptic loosening of femoral components - A review of current and future trends in materials used. Materials \& Design 2012, 42, 459-470.

7. Okulov, I. V., et al., Composition optimization of low modulus and high-strength TiNb-based alloys for biomedical applications. J. Mech. Behav. Biomed. Mater. 2017, 65, 866-871.

8. Malek, J., et al., The effect of $\mathrm{Zr}$ on the microstructure and properties of Ti-35Nb-XZr alloy. Mat. Sci. Eng. a-Struct. 2016, 675, 1-10.

9. Eisenbarth, E., et al., Biocompatibility of beta -stabilizing elements of titanium alloys. Biomaterials 2004, 25 (26), 5705-5713.

10. Cao, W.; Hench, L. L., Bioactive materials. Ceramics International 1996, 22 (6), 493-507.

11. Oh, S.; Jin, S., Titanium oxide nanotubes with controlled morphology for enhanced bone growth. Materials Science \& Engineering, C: Biomimetic and Supramolecular Systems 2006, 26 (8), 1301-1306.

12. Oh, S.-H., et al., Growth of nano-scale hydroxyapatite using chemically treated titanium oxide nanotubes. Biomaterials 2005, 26 (24), 4938-4943.

13. Ghicov, A.; Schmuki, P., Self-ordering electrochemistry: a review on growth and functionality of $\mathrm{TiO}_{2}$ nanotubes and other self-aligned MOx structures. Chem Commun 2009, (20), 2791-2808.

14. Regonini, D., et al., A review of growth mechanism, structure and crystallinity of anodized $\mathrm{TiO}_{2}$ nanotubes. Mat. Sci. Eng. R. 2013, 74 (12), 377-406. 
15. Tsuchiya, H., et al., Nanotube oxide coating on Ti-29Nb13Ta-4.6Zr alloy prepared by self-organizing anodization. Electrochimica Acta 2006, 52 (1), 94-101.

16. Jang, S.-H., et al., Electrochemical characteristics of nanotubes formed on Ti-Nb alloys. Thin Solid Films 2009, 517 (17), 5038-5043.

17. Kim, J.-U., et al., Morphology of hydroxyapatite coated nanotube surface of $\mathrm{Ti}-35 \mathrm{Nb}-\mathrm{xHf}$ alloys for implant materials. Thin Solid Films 2011, 520 (2), 793-799.

18. Campanelli, L. C., et al., Effect of an amorphous titania nanotubes coating on the fatigue and corrosion behaviors of the biomedical Ti-6Al-4V and Ti-6Al-7Nb alloys. $J$. Mech. Behav. Biomed. Mater. 2017, 65, 542-551.

19. Grotberg, J., et al., Thermally oxidized titania nanotubes enhance the corrosion resistance of Ti6A14V. Materials science \& engineering. C, Materials for biological applications 2016, 59, 677-89.

20. Rafieerad, A. R., et al., Toward improved mechanical, tribological, corrosion and in-vitro bioactivity properties of mixed oxide nanotubes on $\mathrm{Ti}-6 \mathrm{Al}-7 \mathrm{Nb}$ implant using multi-objective PSO. Journal of the Mechanical Behavior of Biomedical Materials 2017, 69, 1-18.

21. Hilario, F., et al., Influence of morphology and crystalline structure of $\mathrm{TiO}_{2}$ nanotubes on their electrochemical properties and apatite-forming ability. Electrochimica Acta 2017, 245, 337-349.

22. Yu, W.-q., et al., In vitro corrosion study of different $\mathrm{TiO}_{2}$ nanotube layers on titanium in solution with serum proteins. Colloids and Surfaces B: Biointerfaces 2011, 84 (2), 400-405.

23. Jang, S.-H., et al., Electrochemical characteristics of nanotubes formed on Ti-Nb alloys. Thin Solid Films 2009, 517 (17), 5038-5043.

24. Kim, W.-G.; Choe, H.-C., Nanostructure and corrosion behaviors of nanotube formed Ti-Zralloy. Transactions of Nonferrous Metals Society of China 2009, 19 (4), 1005-1008.

25. Fojt, J., et al., Electrochemical behaviour of the nanostructured surface of Ti-35Nb-2Zr alloy for biomedical applications. Materials and Corrosion 2016, 67 (9), 915-920.

26. Fovet, Y., et al., Influence of $\mathrm{pH}$ and fluoride concentration on titanium passivating layer: stability of titanium dioxide. Talanta 2001, 53 (5), 1053-1063.

27. Nakagawa, M., et al., Effect of fluoride concentration and $\mathrm{pH}$ on corrosion behavior of titanium for dental use. Journal of dental research 1999, 78 (9), 1568-1572.

28. Reclaru, L.; Meyer, J. M., Effects of fluorides on titanium and other dental alloys in dentistry. Biomaterials 1998, 19 (1-3), 85-92.

29. Robin, A.; Meirelis, J. P., Influence of fluoride concentration and $\mathrm{pH}$ on corrosion behavior of Ti-6Al-4V and Ti-23Ta alloys in artificial saliva. Materials and Corrosion 2007, 58 (3), 173-180.

30. Fojt, J., et al., On the increasing of adhesive strength of nanotube layers on beta titanium alloys for medical applications. Applied Surface Science 2015, 355, 52-58.
31. Kar, A., et al., Electrodeposition of hydroxyapatite onto nanotubular $\mathrm{TiO}_{2}$ for implant applications. Surface and Coatings Technology 2006, 201 (6), 3723-3731.

32. Huang, H.-H.; Lee, T.-H., Electrochemical impedance spectroscopy study of Ti-6Al-4V alloy in artificial saliva with fluoride and/or bovine albumin. Dental Materials 2005, 21 (8), 749-755.

33. Joska, L.; Fojt, J., Corrosion behaviour of titanium after short-term exposure to an acidic environment containing fluoride ions. Journal of Materials Science: Materials in Medicine 2010, 21, 8 .

34. Duarte, L. T., et al., Surface characterization of oxides grown on the $\mathrm{Ti}-13 \mathrm{Nb}-13 \mathrm{Zr}$ alloy and their corrosion protection. Corrosion Science 2013, 72, 35-40.

35. Calderon Moreno, J. M., et al., Surface and electrochemical characterization of a new ternary titanium based alloy behaviour in electrolytes of varying $\mathrm{pH}$. Corrosion Science 2013, 77, 52-63.

36. Vasilescu, C., et al., Surface analysis and corrosion resistance of a new titanium base alloy in simulated body fluids. Corrosion Science 2012, 65, 431-440.

37. Barsoukov, E.; MacDonald, R., Impedance Spectroscopy: Theory, Experiment, and Applications, $2^{\text {nd }}$ Edition. 2005; p 608 pp.

38. Bojinov, M., et al., Evidence of coupling between film growth and metal dissolution in passivation processes. Electrochimica Acta 2003, 48 (28), 4107-4117.

39. Ibris, N.; Mirza Rosca, J. C., EIS study of Ti and its alloys in biological media. Journal of Electroanalytical Chemistry 2002, 526 (1-2), 53-62.

40. Bojinov, M., The ability of a surface charge approach to describe barrier film growth on tungsten in acidic solutions. Electrochimica Acta 1997, 42 (23-24), 3489-3498.

41. Córdoba-Torres, P., et al., Electrochemical impedance analysis of $\mathrm{TiO}_{2}$ nanotube porous layers based on an alternative representation of impedance data. Journal of Electroanalytical Chemistry 2015, 737, 54-64.

42. Mohan, L., et al., Electrochemical behaviour and bioactivity of self-organized $\mathrm{TiO}_{2}$ nanotube arrays on Ti-6Al-4V in Hanks' solution for biomedical applications. Electrochimica Acta 2015, 155, 411-420.

43. Mohan, L., et al., Electrochemical behavior and effect of heat treatment on morphology, crystalline structure of selforganized $\mathrm{TiO}_{2}$ nanotube arrays on Ti-6Al-7Nb for biomedical applications. Materials science \& engineering. C, Materials for biological applications 2015, 50, 394-401.

44. Fojt, J., Ti-6Al-4V alloy surface modification for medical applications. Applied Surface Science 2012, 262, 163-167.

45. Munirathinam, B., et al., Influence of crystallite size and surface morphology on electrochemical properties of annealed $\mathrm{TiO}_{2}$ nanotubes. Applied Surface Science 2015, $355,1245-1253$. 